\title{
СЕМАНТИЧЕСКИЕ ПРЕОБРАЗОВАНИЯ КОНЦЕПТА 'СВЯТОЙ' В РУССКОМ ЯЗЫКЕ
}

Исследованию природы концепта в современной лингвистике уделяется большое внимание, но несмотря на то, что понятие концепт можно считать для современной когнитивистики утвердившимся, содержание этого понятия очень существенно варьируется в концепциях разных научных школ и отдельных ученых. Дело в том, что концепт - категория мыслительная, ненаблюдаемая, и это дает большой простор для ее толкования. Изучением концептов в разные годы занимались такие ученые, как Д. С. Лихачев, В. В. Красных, И. А. Стернин, С. Г. Воркачев, В. И. Карасик, Н. Д. Арутюнова и другие.

Среди наметившихся в настоящее время магистральных линий концептуальных исследований мы придерживаемся интегративного подхода, который отражен в работах Г. Г. Слышкина, С. Г. Воркачева. Они рассматривают концепт как многомерное культурно значимое социопсихическое образование в коллективном сознании, имеющее языковое выражение. Концепт «принадлежит сознанию, детерминируется культурой и опредмечивается в языке» (Слышкин 2000: 10). Придерживаясь интегративного подхода в понимании термина, мы акцентируем своё внимание на позиции Ю. С. Степанова (лингвокультурологический подход). Ю. С. Степанов полагал, что «концепт существует в ментальном мире человека не в виде четких понятий, а как 'пучок' представлений, понятий, знаний, ассоциаций, переживаний, сопровождающих слово» (Степанов 2004: 41). Учёный утверждал следующее: 1) концепт - «основная ячейка культуры в ментальном мире человека»; 2) концепт обладает сложной структурой; 3) ключевые концепты - константы культуры (Степанов 2004: 43) Степанов называл концепт «сгустком культуры в сознании человека», и писал, что «это то, в виде чего культура входит в ментальный мир человека, и, с другой стороны, то, посредством чего человек сам входит в культуру» (Степанов 2004: 46).

В рамках данного исследования в понятие концепт мы будем включать следующее: концепт - это то же понятие, но понятие особое - социально 
и культурно значимое, т.е. отражающее ментальность, духовную культуру народа, выраженное в языке. Вместе с тем, разные проявления ментальности по-своему наполняют содержание концепта.

Сегодня все больше осознается роль словарей в духовной жизни общества, в осмыслении культурного наследия народа. Обращение к лексикографическим источникам позволит нам проанализировать описание концепта 'святой' в европейской и русской культурах. Актуальность данного исследования также связана, на наш взгляд, прежде всего с тем, что концепт 'святой’ является показателем культурного состояния общества, ведь отношение к 'святым' ценностям определяет нравственный уровень человека.

Если описание слов при составлении лексикографических материалов зачастую вызывает затруднения, то как дело обстоит с концептами? Ведь культурные компоненты описывать намного труднее, так как это не явление действительности и не фактическое знание. Концепт - «смыслопорождающая структура» (Григорьев 2006: 67), чтобы его понять, необходимо проанализировать все его компоненты.

Святой - ключевой концепт русской культуры, его лексические значения можно подразделить на две большие группы: религиозные (сакральные) и светские (несакральные). Проблема лексикографического описания состоит в том, что соотношение религиозных и светских значений отличается в разных словарях, а во многих культурологических словарях этот концепт и вовсе отсутствует.

Слово святой использовалось в речи славян ещё до появления православия на Руси, следовательно, это слово не было навеяно западной религией и отнюдь не обозначало канонизированных святых. Даже тот факт, что древние христиане избегали эпитетов: sanctus, sanctissimus, говорит, о том, что это слово употреблялось в языческих надписях, которым не хотели подражать христиане (Андреевский 1900: 269). Как отмечает Ю. С. Степанов, у Даля, знатока древней мудрости, в его словаре светские значения отражены полно («духовно и нравственно непорочный, чистый, совершенный; предмет высшего почитания, божественный, небесный; всё заветное, дорогое, связанное с истиною благом. Святая отчизна; Это мой святой долг; Слово свято - нерушимо; Святой угол - где киот и иконьл») (Степанов 2004: 869).

Интересно то, что практически в то же время, что и словарь Даля, выходит Словарь Академии Российской в 1822 году, в котором указано лишь религиозное значение лексемы святой: 1) Всесовершенный, чистый, праведный. Святая Троища. Святый духъ. 2) Основанный на правилах веры. Святыле отизы. Святый человекъ. Святая жизнь. Святые дела. 3) Угодник наслаждающийся вечным блаженством. Праздник всех святых (Словарь Академии Российской 1822: 94).

Можно предположить, что разница в определениях связана с тем, что у Даля - древнее понимание, а в академическом словаре - свойственное тому 
времени. Но в таком случае: откуда в поэзии XIX века столько метафорических значений слова святой? «Святому братству верен» у А. С. Пушкина, «О родина святая» у В. А. Жуковского, «святое вдохновение» у В. К. Кюхельбекера, «святая поэзия» у Е. А. Баратынского и мн. др. Такой богатый колорит примеров говорит о том, что концепт святой использовали в несакральном значении и довольно часто. Но встаёт вопрос, отчего тогда они не указаны в академическом словаре? Это отдельная тема для исследования.

Пик распространения метафорических значений концепта приходится на советские годы. В четырёхтомном словаре русского языка Академии Наук СССР дано 8 значений понятия святой, причём 6 из них - светские (1. Божественный. Святой дух. Святая троица. || Обозначающий предметы или места религиозного поклонения. Святая церковь. Святое евангелие. Святая икона. 2. Проведший жизнь в служении богу. Жития святых. 3. Безгрешный, непорочный. Он думал о святой Татьяне. 4. Глубоко чтимый. Родина святая. 5. Освященный высокой целью. Святое чувство. 6. Такой, который должен быть выполнен в силу своего высокого значения. Святая обязанность. 7. Незыблемый, нерушимый. Что сказано, то свято. 8. Безусловный, полный. Святая правда) (Евгеньева 1988: 59). В словаре синонимов отмечается: непорочный, возвышенный, благородный (Евгеньева 1976: 154). У Ожегова в перечне значений на первых местах стоят светские (Любовь к Родине, Священный долг) (Ожегов 1978: 650). Скорее всего, такое количество светских, несакральных значений объясняется политикой государства в сфере ослабления влияния религии, а также высоким уровнем моральных ценностей у граждан, ведь моральному воспитанию в советское время уделялось большое внимание.

Как же дело обстоит в современности? В словаре Лопатина 1998 года, на первом месте уже стоят религиозные значения, причём из 3 представленных только 1 светское: 1) Рел.: обладающий высшим совершенством и силой, божественный. 2) Истинный величественный и исключительный по важности, высокий. Святое дело. Святая истина. Святая обязанность. Святая любовь к родине. 3) сущ. У христиан: человек, посвятивший свою жизнь церкви и религии, а после смерти признанный небесным покровителем верующих. Почитать святых (Лопатин 1998: 617). В Ассоциативном словаре того же года преобладают религиозные значения (Святая - Богородииа 25; Мария 5; икона 3; Библия 2 и др.; Святой-блаженный 5; Богородица, долг, монах, отеи 2 и др.) (Караулов 1998: 154). Интересно то, что в словаре Совдепии 1998 года понятие святой отсутствует, хотя, как было отмечено ранее, в СССР оно было популярно, а также интересно то, что в культурологических словарях XX века слово 'святой' не встречается (см. словари: Руднёв 1999, Левит 2007).

Обратимся к толковому словарю русского языка конца XX века «Языковые изменения», выпущенному в 2002 году под ред. Г. Н.Скляревской Российской 
академией наук. Концепт 'святой' в этом словаре дан только в религиозных значениях: 1) Исходящий от Бога. Святое евангелие. Святой дух. Святая троuц̧а. 2) Предназначенный для служения Богу. Святая изерковь. Святая вода. 3) Наделенный божественной благодатью. Особенный наш остров, святой, говорит мама. Потехина И. Тёплый дом. ІІ. Тот, кто провёл жизнь в служении Богу. Выставка икон русских святых) (Скляревская 2002: 560).

Исходя из полученных материалов, можно сделать вывод, что пик светских значений приходился на пушкинскую эпоху и советские годы, а сейчас мы наблюдаем тенденцию к отмиранию несакральных значений. Для того, чтобы убедиться в правильности данного утверждения, было проведёно исследование журналистского дискурса. Его цель: выявить характер употребления концепта «святой» в современных СМИ. Для достижения достоверных результатов в работе использовался комплексный метод анализа письменных текстов, включивший в себя: лингвистический анализ концепта по Л. Г. Бабенко, которая предусматривает «обобщение контекстов в рамках употребления ключевого слова» и концентрирует внимание на сочетаемости исследуемого слова с другими (Бабенко 2000: 91); лингвистический анализ 3. К. Тарланова на морфемном и лексико-семантическом уровнях (Тарланов $1995)$; многофакторный анализ текста В. В. Богуславской, которая соотносит анализ текста с историческим, этнокультурным контекстом (Русский язык 2004); дискурсивный подход к анализу концепта по Э. В. Чепкиной (Чепкина $2000)$ и этнофилологический анализ Т. К. Донской (Донская 2007).

Материалом для исследования прежде всего журналистского дискурса выступили современные публицистические издания за период с 1 января по 31 декабря 2014 года, при этом газеты были подобраны в соответствии с популярностью и разнообразием дискурсов. Согласно рейтингу «КОНСАЛТ-ЦЕНТРа» в газетном сегменте в 1 полугодии 2014 года лидировала по проданным тиражам общественно-политическая газета «Аргументы и факты», согласно рейтингу «Медиалогии» самые цитируемые медиаресурсы за 2014 год: «Известия», «Коммерсантъ», «Ведомости», в спортивной отрасли «Спорт-Экспресс», а в региональном рейтинге нашего города и республики лидирует «Вечерняя Казань».

В ходе комплексного анализа газетных публикаций было выявлено:

- для современного журналистского дискурса более характерно употребление религиозного значения концепта 'святой' 76,4\%, что подтверждает наше предположение о снижении несакральных значений.

- в газетах общественно-политического, культурного дискурса доминируют религиозные значения, лишь в спортивном дискурсе светские.

- чаще всего встречаются прилагательные (не зависит от значения).

- наречия встречаются практически только в светских значениях и составляют в среднем $1 / 4$ их часть (наиболее частотны в сочетании «свято верить») 
- в религиозных значениях чаще всего встречается «канонизированный цุерковью», а в светских 1 позицию занимает «дорогой сердиу», также довольно частотны сочетания: святая вера, святое дело и святая отчизна (Русь, Россия и т.д.).

- чаще всего употребляется форма: прилагательное ед. числа, м. рода, родительного падежа, существительные мн. ч. Р. п.

В газетных текстах могут быть представлены крылатые выражения, фразеологизмы. Самые популярные из них: «святая святых» и «свято место пусто не бывает».

Кроме того, были обнаружены несакральные значения, ранее не обозначавшиеся в словарях, к примеру, «светские святые»-современные кумиры, уважаемые люди, и новые сочетания слов, например, название зарубежной футбольной команды «Святые Галленыл, которое часто футбольные комментаторы и корреспонденты сокращают до «святые», «святая политика» (название проекта) и т.д.

Резюмируя вышесказанное, можно отметить, что результаты исследования журналистских текстов подтвердили наше предположение о том, что уровень употребления светских значений концепта 'святой' намного ниже, чем религиозных. Важно отметить, что концепт 'святой', употреблённый в метафорических значениях, в журнальных текстах приобрёл воплощение национальных ценностей (святые: правда, дело, убеждения, обязанности, вера, Победа, Россия, Русь и т.д.). Вероятнее всего, здесь можно отметить сознательное усилие по созданию идеологического подтекста.

Итак, предположение о снижении светских значений концепта 'святой' в современном мире подтверждено результатами исследования современной периодики. Суммируя все данные полученных результатов, в том числе предыдущие (лексикографическое исследование), мы пришли к выводу, что соотношение светских и религиозных значений концепта 'святой' зависит от культурной эпохи. Рассмотренные периоды (древние славяне, средние века, пушкинская эпоха, эпоха СССР, конец ХХв. - начало XXI в.) показали, что пик светских значений приходился на пушкинскую эпоху и советские годы, а сейчас мы наблюдаем тенденцию к отмиранию несакральных значений. Вывод об уменьшении значимости светских значений в современности сделан на основе анализа лексикографических источников и журналистских текстов.

\section{Библиография}

Бабенко Л. Г. (2000), Лингвистический анализ художественного текста: учебник для вузов по специальности филология, ред. Л. Г. Бабенко, И. Е. Васильев, Ю. В. Казарин, Екатеринбург.

Григорьев А. А. (2006), Конщепт и его лингвокультурологические составляющие, «Вопросы философии», № 3, с. 64-67. 
Донская Т. К. (2007), Этнические символь как объект филологического анализа текста, [в:] Язык, сознание, личность. Коммуникация на русском языке в межкультурной среде, Том 4: Мир русского слова и русское слово в мире, София, с. 73-75.

Слышкин Г. Г. (2000), Лингвокультурные концепты прецедентных текстов в сознании и дискурсе, Москва.

Тарланов З. К. (1995), Методы и принципы лингвистического анализа: [учеб. пособие], Петрозаводск.

Чепкина Э. В. (2000), Русский журналистский дискурс: текстопорождающие практики и коды (1995-2000), Екатеринбург.

\section{Словари}

Андреевский И. Е. (1900), Энцииклопедический словарь, Том XXIX, Санкт-Петербург.

Евгеньева А. П. (1976), Словарь синонимов, Ленинград.

Евгеньева А. П. (1988), Словарь русского языка в четырёх томах, Том IV, Москва.

Караулов Ю. Н. (1998), Русский ассоциативный словарь, кн. 5, Ч. ІІІ, Москва.

Культурология. Энщиклопедия. В 2-х m, Том 2 (2007), ред. С. Я. Левит, Москва.

Лопатин В. В., Лопатина Л. Е. (1998), Русский толковый словарь, Москва.

Ожегов С. И. (1978), Словарь русского языка, Москва.

Руднев В. П. (1999), Словарь культуры ХХ века. Ключевые понятия и тексты, Москва.

Скляревская Г. Н. (2002), Толковый словарь русского языка кониа ХХ века. Языковые изменения, Санкт-Петербург.

Словарь Академии Российской по азбучному порядку расположенный, Часть VI (1822), Санкт-Петербург.

Степанов Ю. С. (2004), Константы:: Словарь русской культуры, Москва.

Helena Kolosova, Alexandra Matskevich

\section{SEMANTIC TRANSFORMATIONS OF THE CONCEPT 'СВЯTOЙ' IN THE RUSSIAN LANGUAGE}

(Summary)

The article is devoted to the research of the key concept of the Russian language culture 'святой'. The relevance of the work is predetermined by the growing interest to the formation strategy of values and moral norms in the modern world as well as the culture maintenance in general. The detailed research of the lexical semantic field of the concept allowed making conclusions about transformations of the semantic meaning of the concept in the history of the Russian language: gradual extinction of desacralized meanings was mentioned. Appealing journalistic discourse gave an opportunity to determine the frequency secular and sacred meanings of the concept are being used in the modern Russian language. It has been concluded that proportion of the secular and sacred meanings of the concept “святой" is directly connected to the cultural epoch.

Keywords: conceptual picture of the world, linguocultural concept, Russian language, semantics, lexicography, journalistic discourse. 


\title{
СЕМАНТИЧЕСКИЕ ПРЕОБРАЗОВАНИЯ КОНЦЕПТА 'СВЯТОЙ' В РУССКОМ ЯЗЫКЕ
}

\author{
(Резюме)
}

Данная статья посвящена исследованию ключевого концепта русской лингвокультуры 'святой'. Актуальность данного исследования связана с возросшим интересом в современном мире к стратегии формирования ценностно-нравственных установок общества и поддержания культуры в целом. Детальное исследование лексико-семантического поля заявленного концепта с привлечением лексикографических источников позволило сделать определенные выводы относительно трансформации семантического значения концепта в истории русского языка: отмечается постепенное отмирание несакральных значений. Обращение к журналисткому дискурсу дало возможность установить частотность употребления светских и сакральных значений концепта в современном русском языке. Был сделан вывод о том, что соотношение светских и религиозных значений концепта 'святой' напрямую связано с культурной эпохой.

Ключевые слова: концептуальная картина мира, лингвокультурный концепт, русский язык, семантика, лексикография, журналистский дискурс. 